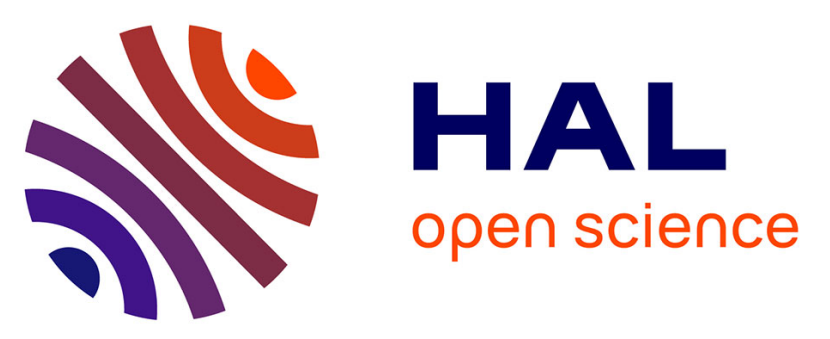

\title{
Ultra large mode area fibers with aperiodic cladding structure for high power single mode lasers
}

Philippe Roy, Romain Dauliat, Aurélien Benoit, Dia Darwich, Jens Kobelke, Kay Schuster, Stephan Grimm, François Salin, Raphaël Jamier

\section{- To cite this version:}

Philippe Roy, Romain Dauliat, Aurélien Benoit, Dia Darwich, Jens Kobelke, et al.. Ultra large mode area fibers with aperiodic cladding structure for high power single mode lasers. Workshop on Specialty Optical Fibers and Their Applications, Nov 2015, Hong-Kong, Kowloon, China. hal-01250383

\section{HAL Id: hal-01250383 \\ https://hal.science/hal-01250383}

Submitted on 5 Jan 2016

HAL is a multi-disciplinary open access archive for the deposit and dissemination of scientific research documents, whether they are published or not. The documents may come from teaching and research institutions in France or abroad, or from public or private research centers.
L'archive ouverte pluridisciplinaire HAL, est destinée au dépôt et à la diffusion de documents scientifiques de niveau recherche, publiés ou non, émanant des établissements d'enseignement et de recherche français ou étrangers, des laboratoires publics ou privés. 


\title{
Ultra large mode area fibers with aperiodic cladding structure for high power single mode lasers
}

\author{
Philippe Roy, ${ }_{1}^{1}$ Romain Dauliat, ${ }^{1,2}$ Aurélien Benoît, ${ }^{1}$ Dia Darwich, ${ }^{1}$ Jens Kobelke, ${ }^{2}$ Kay Schuster, ${ }^{2}$ \\ Stephan Grimm, ${ }^{2}$ François Salin $^{3}$ and Raphaël Jamier ${ }^{1}$ \\ ${ }^{I}$ Univ.Limoges, CNRS, XLIM, UMR 7252, F-87000 Limoges, France \\ ${ }^{2}$ Leibniz Institute of Photonic Technology, Albert-Einstein-Straße 9, 07745 Jena, Germany \\ ${ }^{3}$ Eolite Systems, 11 avenue de la Canteranne 33600 Pessac, France \\ Author e-mail address: philippe.roy@xlim.fr
}

\begin{abstract}
This communication presents the latest designs, fabrication steps and first results of large mode area fibres with aperiodic cladding structure for high power singlemode emission. Precompensation of thermal loading and first laser emission are detailed.

OCIS codes: (140.3510) Lasers, fiber; (060.2280) Fiber design and fabrication; (060.5295) Photonic crystal fibers; (140.3295) Laser beam characterization; (160.2290) Fiber materials
\end{abstract}

\section{Introduction}

During the two last decades, the achievement of microstructured fiber technologies has enable an impressive power scaling of fiber laser devices [1]. Non-linear processes and mid/long-term degradations like photo-darkening have been successively fended off by new generation of Very Large Mode Area (VLMA) fibers. Among them, rod-type microstructured fibers, Distributed Modal Filtering fibers (DMF) [2] and Large-Pitch-Fibers (LPF) [3] are significant examples while we consider pulsed and/or narrow bandwidth lasers that require a particular attention to nonlinear drawbacks. More recently, modal instabilities resulting from thermal loading have been clearly identified as the current limitation that hampers any further improvement of fiber laser performances. Both design and technology improvements are therefore implemented in our group with the following combined objectives: strengthen the laser beam quality and its stability at high-power level while simplifying and reducing the cost of fiber manufacturing.

\section{Fiber concept and modeling}

The fiber concept implemented in this work consists in breaking the inner cladding symmetries of the fiber structure in order to exacerbate the delocalization of High-Order Modes (HOM) out of the gain region. Indeed, a detailed theoretical study has shown that the confinement of the fundamental mode does not suffer from these modifications whereas HOMs are efficiently delocalized in the passive region out of the active core, minimizing their parasitic participation to the amplification process. Figure 1.a (resp. 1.b) shows the refractive index profile (resp. the cross section) of our triple-clad VLMA fibers referred as Fully-Aperiodic LPF (FA-LPF). Such an aperiodic lattice may be indifferently used for the high-index structure or low-index ones. In figure 1.a, the background material of the structure is made of high-index passively doped silica (clear blue) matching the refractive index of the Al-Yb-doped active core (red) whereas low-index inclusions are made of pure silica (dark blue) or more generally low-index silica.

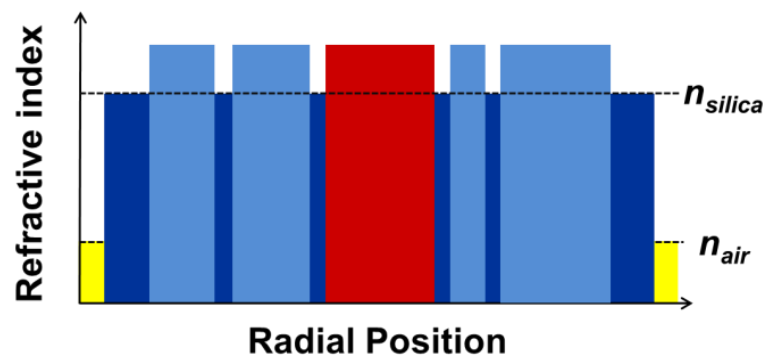

(a)

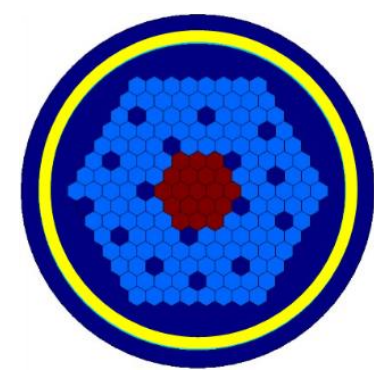

(b)

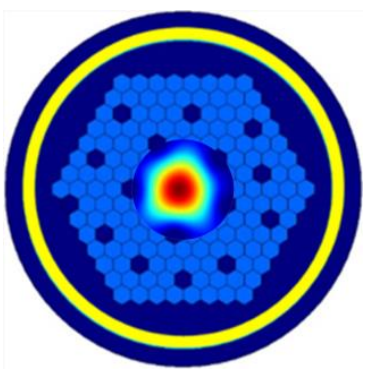

(c)

Fig. 1: (a) Schematic representation of the refractive index profile and (b) Cross-section of the triple-clad fully-aperiodic fiber. The gain region is represented in red, the index-matched passive material in light blue, the pure silica inclusions and trench are depicted in dark blue whereas the yellow area stands for the air-clad. (c) Computed intensity distribution of the fundamental mode propagated into the FA-LPF. 
In low-index structures, that are not depicted here, the background material is made of pure silica, the low-index inclusions are made of F-doped silica and active material is made of index compensated Yb-doped silica (possibly $\mathrm{F} / \mathrm{Al}-\mathrm{Yb}$ filamented cores). The outer part is made of pure silica and an air-clad (in yellow in figure 1) is implemented to ensure the propagation of the multimode pump radiation, leading to the so-called triple-clad design. As reported in [4], this fiber structure could offer an improvement regarding the singlemodeness and the thermal resilience. Unlike most of the common VLMA fibers, the value of the core refractive index may take any value because that of the surrounding background material is chosen to be adjustable. This enables an efficient mitigation of photodarkening [5,6] and Brillouin gain [7] because of a real freedom in core glass composition. The only technical constraint, as for standard VLMA fibers, is the perfect index-matching that is required between the gain material and the surrounding passive glass (whatever the high or low-index design). In figure 1.c, the calculated fundamental mode is superimposed on the fiber cross-section.

That having been said, one must admit that the proposed improvements on the modal selection may remain incremental in practical situations if the thermal issues associated with laser operation are neglected. Indeed, the thermal loading implies a gradual modification of the refractive index profile and for extreme situations, the influence of the cladding microstructure remains negligible compared to that of the thermally-induced refractive index profile [8]. However, for realistic situations with regard to current industrial applications, when the pump power ranges from $100 \mathrm{~W}$ to $1 \mathrm{~kW}$, our design may offer relevant additional degrees of freedom to fight against thermal impairments. Figure 2 shows the comparison between a standard LPF, a non-compensated FA-LPF and a thermally compensated FA-LPF. The corresponding refractive indices and cross-sections will be explicated during the conference.

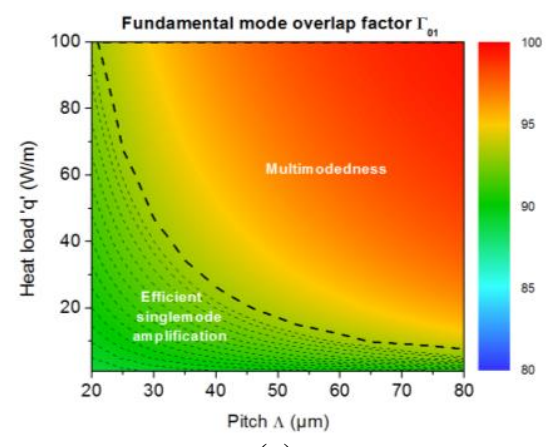

(a)

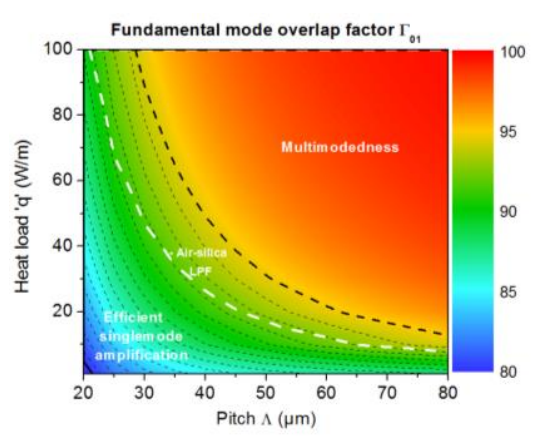

(b)

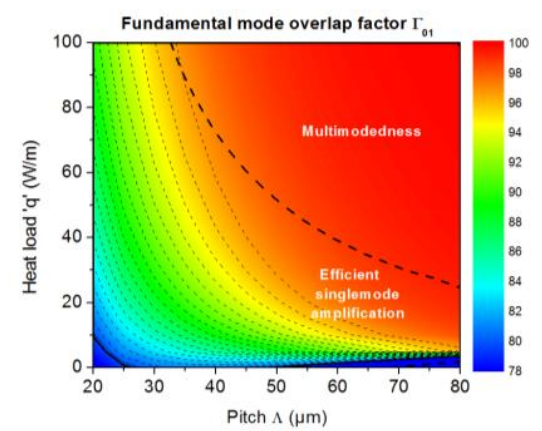

(c)

Fig. 2: Schematic representation of the singlemode/multimode domains versus thermal loading for (a) standard LPF (b) FA-LPF and (c) pre-compensated FA-LPF.

\section{Experimental results}

The fully-aperiodic fiber concept has already been validated as passive fiber [9]. We will briefly recall the main results demonstrated with low-index aperiodic structures in which the propagation of a unique mode has been observed up to a mode field area of $15,000 \mu \mathrm{m}^{2}$ at $\lambda=2 \mu \mathrm{m}$ (resp. $6,500 \mu \mathrm{m}^{2}$ at $\lambda=1 \mu \mathrm{m}$ ).

More recently, we have fabricated an Yb-doped solid FA-LPF whose the cross-section image is depicted in figure 3.a. The central bright region stands for both high-index materials (actively and passively-doped regions cannot be distinguished on the image) while the grey areas are made of pure silica. The black area is the air cladding. The average core dimensions, measured in between two low-index inclusions diametrically opposed, are about $40 \mu \mathrm{m}$ in this very first fiber, yielding into a mode field area of $920 \mu \mathrm{m}^{2}$. The outer diameter is about $1.2 \mathrm{~mm}$. The air-clad (dark area in figure 3.a) exhibits an internal diameter of $210 \mu \mathrm{m}(\mathrm{NA}=0.4)$. A continuous-wave laser has been built from a $90 \mathrm{~cm}$-long piece of this triple-clad fully-aperiodic rod-type fiber. Details of the experiment will be given during the conference. 


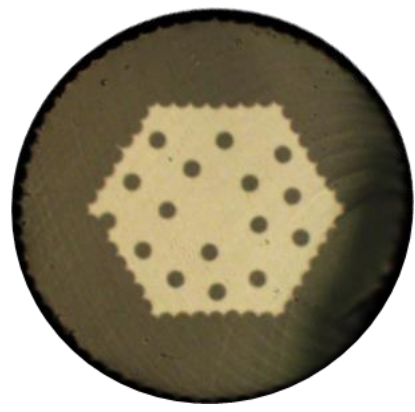

(a)

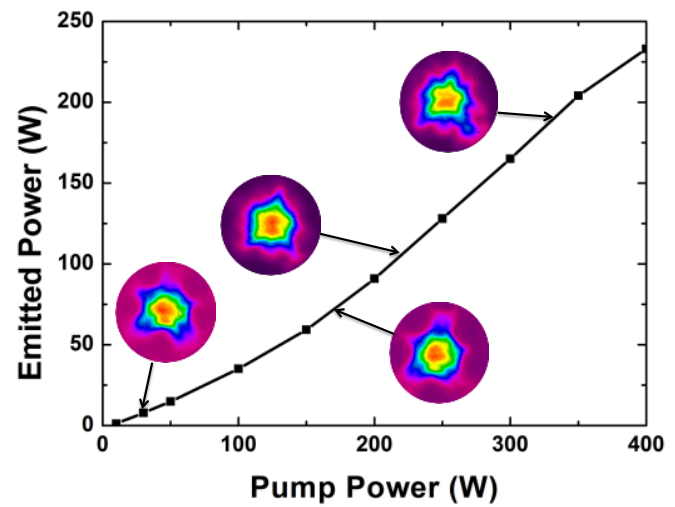

(b)

Fig. 3: (a) Image of the cross-section of the fabricated Yb-doped FA-LPF. (b) Evolution of the measured extracted signal output power versus the incident pump power. Insets: Images of the near-field intensity distributions measured for different output power.

The evolution of the extracted laser power with respect to the incident pump power is shown in figure 2.b. The slope efficiency with respect to the incident pump power has reached $60 \%$. The measured intensity pattern of the emitted beam is similar to that calculated (see figure 1.c). Preliminary $\mathrm{M}^{2}$ measurements have been performed for power levels lower than $100 \mathrm{~W}$ and versus different axis, the measured values are always smaller than 1.3. The beam characterizations will be shown during the conference.

\section{Conclusions}

In this work, we have theoretically demonstrated the benefits of a new fully-aperiodic large pitch fiber. For a cold fiber (low pump power) or passive fiber, the FA-LPF enhances the delocalization of HOMs, the singlemodeness and the beam stability being then improved. This has been theoretically studied and verified with a passive fiber. When thermal loading occurs, a pre-compensation strategy can be deployed to significantly push away modal instabilities. Finally, a first active fiber prototype has been fabricated and some major technological challenges have already been overcome. We report here the associated results among which the efficient emission of a stable $\mathrm{CW}$ beam up to $230 \mathrm{~W}$ output power.

This work, conducted under the AVANTAGE project, was co-funded by the European Union and Eolite Systems. $E C$ is involved in the Région Limousin with the "Fonds européen de développement économique et régional". Financial support by the Thuringian Ministry of Economics, Labor, and Technology (TMWAT) under contract 2011 FGR 0104 (FG Faser-Tech), with financial support from the European Social Fund (ESF) is gratefully acknowledged.

\section{References}

[1] M.N. Zervas et al., IEEE Journal of selected topics in Quantum Electronics, vol. 20, n5, 2014

[2] E. Coscelli et al. J. Light. Technol., vol. 30, n²2, pp. 3494-3499, 2012

[3] J. Limpert, et al., Light Sci. Appl., vol. 1, e8, 2012

[4] R. Dauliat et al. in Proc. SPIE 9507, Micro-structured and Specialty Optical Fibres, p. 950709, 2015

[5] S. Jetschke et al. Appl. Opt., vol. 51, n³2, pp. 7758-7764, 2012

[6] M. Engholm et al., Opt. Lett., vol. 34, n8, pp. 1285-1287, 2009

[7] P. D. Dragic et al., Opt. Mat., vol. 35, pp. 1627-1632, 2013

[8] H.J. Otto et al., Opt. Lett., vol. 39, n²2, pp. 6446-6449, 2014

[9] A. Benoît et al., Opt. Lett, vol. 39, n 15, pp 4561-4564, 2014 